\title{
Motor functions, quality of life and maternal anxiety and depression in children with cerebral palsy of different intelligence levels
}

\author{
Elif Akçay ${ }^{1 \oplus}$, Yaşar Tanır ${ }^{2 \oplus}$, Serap Tıraş Teber ${ }^{3 \oplus}$, Birim Günay Kılıç \\ ${ }^{1}$ Department of Child and Adolescent Psychiatry, Ankara City Hospital, Ankara, Turkey ${ }^{2}$ Department of Child and Adolescent \\ Psychiatry, İstanbul University Faculty of Medicine, İstanbul; Departments of ${ }^{3}$ Pediatric Neurology and ${ }^{4}$ Child and Adolescent \\ Psychiatry, Ankara University Faculty of Medicine, Ankara, Turkey.
}

\begin{abstract}
Background. Cerebral palsy (CP) is the most common motor disability in childhood. In addition to motor impairment, it is frequently accompanied by intellectual disability (ID). We aimed to investigate the associations between motor functions, quality of life (QoL) and maternal psychopathology in children with CP of different intelligence levels.

Methods. In total, 37 children and adolescents (16 females and 21 males) between 4 and 18 years of age diagnosed with CP were recruited from a Pediatric Neurology Outpatient Clinic. Gross Motor Function Classification System (GMFCS) and Bimanual Fine Motor Function (BFMF) were used for the children's motor functions assessment. Quality of life was determined by the caregivers with Pediatric Quality Of Life Inventory-Parent version (PedsQL-P). Maternal anxiety and depression levels were assessed using Beck Anxiety Inventory (BAI) and Beck Depression Inventory (BDI).

Results. Moderate-severe ID ( $\mathrm{n}=19)(13.5 \%, 37.8 \%)$ and normal IQ-mild ID ( $=18)(32.4 \%, 16.2 \%)$ groups were evaluated in this study. GMFCS level 2 was more frequent in both groups. The majority of the severe-moderate ID group was at BFMF level 4, while the normal IQ-mild ID group was at BFMF level 2. PedsQL-P scores of children with CP, maternal BAI scores, and maternal BDI scores did not differ between the two groups ( $\mathrm{p}>0.05$ ). Psychosocial PedsQL scores had a moderate negative correlation with the maternal BAI scores $(\mathrm{r}=-0.41, \mathrm{p}<0.05)$. There was also a moderate positive correlations between the ages of children and maternal BDI scores ( $\mathrm{r}=0.34$, $\mathrm{p}<0.05)$.

Conclusions. Our results demonstrated that maternal anxiety was correlated with psychosocial QoL in children with CP. Maternal depression scores increasing with the ages of the children with CP may also indicate the social support needs for mothers with children of chronic diseases. Further studies may reveal the associations with other biopsychosocial factors in children with $\mathrm{CP}$ of different intelligence levels by using longitudinal study designs with larger sample sizes.
\end{abstract}

Key words: anxiety, depression, cerebral palsy, child, quality of life.

Cerebral palsy $(\mathrm{CP})$ is the most common motor disability in childhood. ${ }^{1}$ Cerebral palsy (CP) is described as a nonprogressive neuromotor disorder that mainly affects the development of movement, muscle tone, and posture. ${ }^{2} \mathrm{CP}$

Elif Akçay
elifbayram07@gmail.com

Received 13th January 2021, revised 13th February 2021, accepted 24th February 2021. umbrella refers to very heterogeneous clinical presentations in children. In addition to motor impairments, there may be impairments in cognition, communication, hearing, vision, behavior, and epilepsy that may worsen the motor impairment, function, and quality of life (QoL). ${ }^{3,4}$

The most common comorbidities according to the Surveillance of Cerebral Palsy in Europe (SCPE) are speech/language impairments 
(71\%), severe intellectual disability (ID) (62\%), epilepsy (39\%), and visual impairment (22\%). ${ }^{3}$ $\mathrm{CP}$ is accompanied by different levels of ID. ${ }^{5}$ Gabis and her colleagues' study ${ }^{6}$ reported that $22.5 \%$ of children with $\mathrm{CP}$ had normal intelligence, and $41.3 \%$ had moderate or severe ID. Moreover, it was suggested that more severe motor function impairments are associated with higher ID. ${ }^{6}$ Bertoncelli et al. ${ }^{7}$ reported that poor motor skills and epilepsy were associated with severe ID.

Severe motor function impairment in children with CP has been found to be more related to poor QoL in terms of physical health and autonomy. Additionally, children with low intelligence quotient (IQ) were found to have a higher risk of poor QoL in terms of social support. ${ }^{8}$ Mobility performances relate to gross motor function levels; however, daily activities mostly depend on children and adolescents' intellectual ability with CP. ${ }^{9}$ Caregiving a child who has limited self-mobility is highly psychologically and physically demanding. ${ }^{10,11}$ Parents must spend more time caring for children with $\mathrm{CP}$ who have limited self-mobility. Greater limited self-mobility in children with $\mathrm{CP}$ is associated with greater stress and depressive symptoms among their mothers. ${ }^{12}$ Because mothers are mostly primary caregivers, and important team workers of the rehabilitation and care services of children with cerebral palsy, they suffer from many socio-emotional problems and report higher anxiety levels. ${ }^{13,14}$ Mothers of children with $\mathrm{CP}$ have been found to show depressive symptoms and poor QoL, and it was reported that $30 \%$ of mothers having $\mathrm{CP}$ children showed symptoms of depression..$^{15}$ Also, the prevalence of depression was reported at $20 \%$ to $30 \%$ in mothers of children with ID. ${ }^{16,17}$ The mothers of children with ID reported that they were socially isolated due to caregiving their children and neglected their own social needs. Moreover, caregivers often neglect to receive mental health support for their own self-care needs. ${ }^{18,19}$

Consequently, since about half of children with $\mathrm{CP}$ have $\mathrm{ID}^{20}$, more information is needed about the areas of life for children with $\mathrm{CP}$ who also have ID. Quality of life assessment is increasingly used as a mechanism to gain insight into a child's life, identify positive or challenging areas of life, and evaluate interventions. Psychopathology of caregivers may affect the QoL of children by causing inadequate care. Parents with psychiatric problems may subjectively evaluate their children's functionality more negatively. Moreover, it has been reported that caregivers of children with poor QoL experience more psychiatric problems than caregivers of healthy children. ${ }^{13,21}$ In this study, we aimed to investigate the parent-proxy QoL of children with $\mathrm{CP}$ according to the severity of intelligence levels. In addition to QoL, we examined depression and anxiety in mothers of children with $\mathrm{CP}$ to identify challenges in $\mathrm{CP}$ children with severe ID.

\section{Material and Methods}

\section{Participants and Procedures}

In total, 37 children and adolescents (16 females and 21 males) between 4 and 18 years of age diagnosed with $\mathrm{CP}$ were recruited from a Pediatric Neurology Outpatient Clinic between April 2018 and September 2018. Also, 37 primary caregivers (all mothers) of children and adolescents with $\mathrm{CP}$ were invited to participate in the study. The participants were assessed by a child neurologist for the diagnosis of $\mathrm{CP}$, their mother's literacy status, and abilities to fill out the questionnaires. Participants who reported any genetic disorder, severe visual and auditory impairments, neurological disorders except for epilepsy (e.g., acute cranial trauma, brain tumors) were not included in the study.

Ethical approval was obtained from the Ankara University Medical School Research Ethics Committee (ID-No: 04-215-18). Informed written consent was obtained from parents, and written assent was obtained from children and adolescents.

After the evaluation of the inclusion and exclusion criteria, sociodemographic and clinical 
assessments were performed. Age, gender, family income levels, gestational age, maternal age, paternal age, birth weight, prematurity, types of birth, and presence of epilepsy, receiving special education were recorded. The cerebral palsy type was determined as spastic (hemiplegic, diplegic, tetraplegic), dyskinetic (athetosis, dystonia), ataxic or mixed types according to the "Surveillance of European Cerebral Palsy Group". ${ }^{22}$ Gross Motor Function Classification System (GMFCS) and Bimanual Fine Motor Function (BFMF) were used for motor function assessment of the children by the child neurologist. GMFCS consists of five levels; from Level I (the most independent motor function) to Level $\mathrm{V}$ (the most restricted voluntary control of movement and ability to maintain postures, the most dependent motor function). ${ }^{23}$ BFMF is designed to evaluate the upper extremity performance in children's daily living activities. Manipulation and gripping ability are evaluated at five levels. Scoring of GMFCS and BFMF are mostly in parallel with each other. $^{24}$

The children's intelligence levels were evaluated by the Turkish version of the Wechsler Intelligence Scale for Children-Revised (WISC-R), Stanford-Binet Intelligence Test, and Ankara Developmental Screening Inventory (ADSI). The children with cerebral palsy were divided into two groups according to their intelligence levels; (i) Normal Intelligence Quotient (IQ)-Mild Intellectual Disability (ID) and (i) Moderate-Severe ID. Quality of life of the sample was determined by their caregivers with the Pediatric QOL Inventory, Parent version (PedsQL-P). Maternal anxiety and depression levels were assessed by using Beck Anxiety Inventory (BAI) and Beck Depression Inventory (BDI).

\section{Questionnaires}

Pediatric QOL Inventory-Parent version (PedsQL-P): The PedsQL-P was used to assess health-related quality of life (HRQOL) during childhood. It has two subscales, psychosocial and physical health, and a total score, higher PedsQL-P scores indicate better HRQL. The reliability and validity of the PedsQL-P has been conducted in Turkish children and adolescents. . $^{25,26}$

Beck Anxiety Inventory (BAI): The BAI is a self-report scale used to assess the severity of anxiety symptoms. It is a Likert-type scale that is scored between " 0 " and " 3 " and comprises 21 items. Higher BAI scores indicate higher anxiety levels. The reliability and validity of the BAI has been conducted in Turkish populations. ${ }^{27}$

Beck Depression Inventory (BDI): The BDI is a self-report inventory used to assess the severity of depression symptoms. The scale is composed of 21 items that are scored between " 0 " and " 3 ". Higher BDI scores indicate higher depression levels. The reliability and validity of the BDI has been conducted in Turkish populations. ${ }^{28}$

\section{Intelligence Tests}

Wechsler Intelligence Scale for ChildrenRevised (WISC-R) is used for intelligence assessment of children between the ages of 6 and 16 years. ${ }^{29}$ The reliability and validity of the Turkish version has been conducted in Turkish children. ${ }^{30}$ The intelligence level of the child is classified as normal, borderline, mild, moderate, and severe with WISC-R scores. Stanford-Binet Intelligence Test was used to assess children between the ages of 2 and 16 years and adapted to Turkish by Uğurel-Şemin. ${ }^{31}$ The intelligence level is determined according to the standard scores in this test. Ankara Developmental Screening Inventory (ADSI) was used for determining the developmental levels of young children in Turkey. ${ }^{32}$ It was administered to caregivers of children who were unable to express themselves, could not communicate, and could not be applied the WISC-R, StanfordBinet test due to their intellectual levels. The ADSI includes 154 questions which assess 5 domains (language, cognitive, fine motor function, gross motor function, sociality, and self-care abilities) asked to the caregivers and are combined with the clinical observation 
of the child for determining their intellectual levels. The total scores of these subscales give the general intellectual-developmental levels which are determined according to normative data matched for age.

\section{Statistical analysis}

We used the Shapiro-Wilk test to analyze data that was not normally distributed. According to the normal distribution, descriptive statistics were presented as mean \pm standard deviation or median (min-max). Count and percentages were used to describe categorical variables; Continuous clinical variables were analyzed using Independent t-tests or the MannWhitney $U$ test according to their distribution characteristics in group comparisons. Differences in categorical variables between the groups were examined using Pearson's chisquared and Fisher exact analysis. Data analysis was performed using Statistical Package for the Social Sciences (SPSS) version 23.0, (IBM SPSS Statistics; New York, USA), and all statistical tests were two-tailed with the significance level set at $\alpha=.05$. Spearman's correlation coefficient was calculated to investigate the association among the clinical measures.

\section{Results}

Thirty-seven participants were included in the study; 19 of them were children with moderatesevere ID (moderate: $13.5 \%$, severe: $37.8 \%$ ), 18 of them were children with normal IQ (32.4\%) or mild ID (16.2\%). There were no differences in age, maternal age, paternal age, and family income levels between the two groups ( $p>0.05)$. Perinatal factors (gestational age, birth weight, prematurity) were not different in the groups; however, there were differences in types of birth, gender, and presence of epilepsy ( $\mathrm{p}=$ $0.012, p=0.012, p=0.012$, respectively). Children with $\mathrm{CP}$ received special education for learning needs (Normal IQ-mild ID group: $77.8 \%$; Moderate-severe ID group: 73.7\%), and for their motor disabilities (Normal IQ-mild ID group: 88.9\%; Moderate-severe ID group: $84.2 \%$ ).
The CP types examinations indicated that the frequency of the spastic type was highest in both groups, and most of these children were spastic bilateral hemiplegia (Normal IQ-mild ID group: 55.6\%; Moderate-severe ID group: $47.4 \%)$. GMFCS level 2 was more frequent in both groups according to gross motor functions examination of the children. There were no differences in severity of gross motor function (level 1-3=non-severe; level 4-5=severe) between the two groups $(p=0.197)$. The majority of the severe-moderate ID group was at BFMF level 4, while the normal IQ-mild ID group was at BFMF level 2. There was a significant difference in severity of bimanual fine motor function (level 1-3= non-severe; level 4-5= severe) between the two groups $(X 2(1, \mathrm{~N}=37)=17.79, \mathrm{p}<0.001)$. Sociodemographic and clinical characteristics of the sample are shown in Table I.

Total PedsQL-P scores, Psychosocial PedsQL-P scores, Physical PedsQL-P scores of children with CP did not differ between normal IQ-mild ID group and moderate-severe ID group $(t(35)=$ $-.809, \mathrm{p}=.424 ; \mathrm{t}(35)=.098, \mathrm{p}=0.922 ; \mathrm{t}(35)=-.088$, $\mathrm{p}=.930$, respectively). There were no differences in maternal BAI scores $(\mathrm{U}=151.00, \mathrm{z}=-0.610, \mathrm{p}$ $=.558)$ and maternal BDI scores $(\mathrm{U}=156.50, \mathrm{z}=$ $-0.7443, \mathrm{p}=.663$ ) between two groups. . Results of maternal psychopathology and quality of life scores between the two groups are shown in Table II.

The correlations among the perinatal factors, gross and fine motor functions, intelligence levels, maternal anxiety scores, maternal depression scores, and PedsQL scores were calculated. Psychosocial PedsQL scores had a moderate negative correlation with the maternal BAI scores. PedsQL scores did not correlate with the other variables included in the correlational analyses. There were also moderate positive correlations between the children's ages and maternal BDI scores. There were also moderate positive correlations between epilepsy and female gender, GMFCS levels, and high negative correlations among the intelligence levels and BFMF level scores. All of the bivariate correlations between the variables are presented in Table III. 
Table I. Sociodemographic and clinical characteristics of the sample.

\begin{tabular}{|c|c|c|c|}
\hline & $\begin{array}{c}\text { Normal IQ-mild ID } \\
(\mathrm{n}=18)\end{array}$ & $\begin{array}{c}\text { Moderate-severe ID } \\
(\mathrm{n}=19)\end{array}$ & $p$ \\
\hline Age (mean \pm SD) (year) & $9.88 \pm 3.68$ & $11.65 \pm 4.92$ & 0.226 \\
\hline Gender & & & $0.012^{*}$ \\
\hline Male & $14(77.8 \%)$ & $7(36.8 \%)$ & \\
\hline Female & $4(22.2 \%)$ & $12(63.2 \%)$ & \\
\hline Maternal age $($ mean \pm SD) & $37.74 \pm 7.58$ & $39.68 \pm 6.33$ & 0.404 \\
\hline Paternal age (mean \pm SD) & $41.72 \pm 7.61$ & $44.15 \pm 7.41$ & 0.331 \\
\hline Family income & & & 0.638 \\
\hline Low & $8(44.4 \%)$ & $7(36.8 \%)$ & \\
\hline Middle-high & $10(55.6 \%)$ & $12(63.2 \%)$ & \\
\hline Gestational age (weeks) & $34.66 \pm 5.50$ & $35.84 \pm 4.89$ & 0.496 \\
\hline Birth weight (grams) & $2435.55 \pm 1115.90$ & $2644.73 \pm 952.26$ & 0.543 \\
\hline Prematurity & $10(55.6 \%)$ & $8(42.1 \%)$ & 0.413 \\
\hline Types of birth & & & $0.012^{*}$ \\
\hline Vaginal birth & $6(33.3 \%)$ & $9(47.4 \%)$ & \\
\hline $\mathrm{C} / \mathrm{S}$ & $12(66.7 \%)$ & $10(52.6 \%)$ & \\
\hline Epilepsy & $4(22.2 \%)$ & $12(63.2 \%)$ & $0.012^{*}$ \\
\hline Special education for cognitive ability & & & 0.538 \\
\hline Yes & $14(77.8 \%)$ & $14(73.7 \%)$ & \\
\hline No & $4(22.2 \%)$ & $5(26.3 \%)$ & \\
\hline Special education for motor ability & & & 0.527 \\
\hline Yes & $16(88.9 \%)$ & $16(84.2 \%)$ & \\
\hline No & $2(11.1 \%)$ & $3(15.8 \%)$ & \\
\hline $\mathrm{CP}$ type & & & N/A \\
\hline Spastic bilateral hemiplegia & $10(55.6 \%)$ & $9(47.4 \%)$ & \\
\hline Spastic unilateral hemiplegia & $5(27.8 \%)$ & $4(21.1 \%)$ & \\
\hline Dystonic & - & $1(5.3 \%)$ & \\
\hline Ataxic & $2(11.1 \%)$ & $2(10.5 \%)$ & \\
\hline Mixed & $1(5.6 \%)$ & $3(15.8 \%)$ & \\
\hline GMFCS & & & N/A \\
\hline Level 1 & $6(33.3 \%)$ & $2(10.5 \%)$ & \\
\hline Level 2 & $7(38.9 \%)$ & $8(42.1 \%)$ & \\
\hline Level 3 & $1(5.6 \%)$ & $1(5.3 \%)$ & \\
\hline Level 4 & $1(5.6 \%)$ & $3(15.8 \%)$ & \\
\hline Level 5 & $3(16.7 \%)$ & $5(26.3 \%)$ & \\
\hline BFMF & & & N/A \\
\hline Level 1 & $8(44.4 \%)$ & $1(5.3 \%)$ & \\
\hline Level 2 & $3(16.7 \%)$ & $2(10.5 \%)$ & \\
\hline Level 3 & $6(33.3 \%)$ & $2(10.5 \%)$ & \\
\hline Level 4 & $1(5.6 \%)$ & $9(47.4 \%)$ & \\
\hline Level 5 & - & $5(26.3 \%)$ & \\
\hline
\end{tabular}

CP: cerebral palsy, C/S: cesarian section, GMFM: gross motor function measure, BFMF: bimanual fine motor function, IQ: intelligence quotient, ID: intellectual disability, SD: standard deviations. N/A: not applicable. ${ }^{*} \mathrm{p}<0.05$. 
Table II. Quality of life scores and maternal psychopathology scores of the sample.

\begin{tabular}{lccc}
\hline & $\begin{array}{c}\text { Normal IQ-mild ID } \\
(\mathrm{n}=18)\end{array}$ & $\begin{array}{c}\text { Moderate-severe ID } \\
(\mathrm{n}=19)\end{array}$ & $\mathrm{p}$ \\
\hline Psychosocial PedsQL-P (mean \pm SD) & $58.17 \pm 21.12$ & $57.51 \pm 19.30$ & 0.922 \\
Physical PedsQL-P (mean \pm SD) & $56.67 \pm 22.20$ & $57.36 \pm 24.78$ & 0.930 \\
Total PedsQL-P (mean \pm SD) & $55.48 \pm 16.09$ & $59.97 \pm 17.56$ & 0.424 \\
BAI (mother) (median)(range) & $11.50(1-38)$ & $13.50(0-47)$ & 0.558 \\
BDI (mother) (median)(range) & $11.36(2-35)$ & $11.72(0-25)$ & 0.663 \\
\hline
\end{tabular}

PedsQL-P: the pediatric quality of life inventory parent version, BAI: beck anxiety inventory, BDI: beck depression inventory, IQ: intelligence quotient, ID: intellectual disability, SD: standard deviations.

Table III. Intercorrelations among study variables.

\begin{tabular}{|c|c|c|c|c|c|c|c|c|c|c|c|c|c|}
\hline & 2 & 3 & 4 & 5 & 6 & 7 & 8 & 9 & 10 & 11 & 12 & 13 & 14 \\
\hline 1.Age & -0.19 & 0.03 & -0.08 & -0.01 & -0.06 & 0.07 & -0.07 & -0.08 & 0.29 & $0.34^{*}$ & $\begin{array}{l}-0.18 \\
\end{array}$ & 0.12 & -0.04 \\
\hline 2.Gender & & -0.07 & -0.23 & 0.13 & 0.28 & $0.37^{*}$ & $-0.45^{* *}$ & $0.33^{*}$ & 0.03 & -0.14 & 0.20 & 0.23 & 0.25 \\
\hline 3.Gestational Age & & & $0.78^{* *}$ & $-0.87^{* *}$ & -0.21 & -0.00 & 0.05 & -0.03 & -0.11 & 0.03 & 0.25 & 0.21 & 0.19 \\
\hline 4.Birth Weight & & & & $-0.74^{* *}$ & -0.27 & 0.04 & -0.01 & -0.18 & -0.01 & -0.01 & 0.09 & -0.01 & 0.01 \\
\hline 5.Prematurity & & & & & 0.17 & 0.05 & 0.003 & -0.08 & 0.03 & 0.003 & -0.19 & -0.05 & -0.07 \\
\hline 6.GMFCS & & & & & & $0.64^{* *}$ & -0.31 & $0.38^{*}$ & 0.11 & 0.13 & -0.03 & -0.02 & 0.04 \\
\hline 7.BFMF & & & & & & & $-0.72^{* *}$ & 0.28 & 0.18 & 0.12 & -0.13 & -0.01 & -0.05 \\
\hline 8.Intelligence level & & & & & & & & $-0.38^{*}$ & -0.30 & -11 & 0.14 & 0.01 & 0.01 \\
\hline 9.Epilepsy & & & & & & & & & -0.01 & -0.09 & 0.00 & 0.05 & 0.16 \\
\hline 10.BAI (mother) & & & & & & & & & & $0.65^{* *}$ & $-0.41^{*}$ & -0.03 & -0.20 \\
\hline 11.BDI (mother) & & & & & & & & & & & -0.32 & 0.11 & -0.13 \\
\hline 12.Psychosocial PedsQL-P & & & & & & & & & & & & $0.49^{* *}$ & $0.72^{* *}$ \\
\hline 13.Physical PedsQL-P & & & & & & & & & & & & & $0.81^{* *}$ \\
\hline 14.Total PedsQL-P & & & & & & & & & & & & & \\
\hline
\end{tabular}

GMFM: gross motor function measure, BFMF: bimanual fine motor function, BAI: beck anxiety inventory, BDI: beck depression inventory, PedsQL-P: the pediatric quality of life inventory. Parent version. ${ }^{*}<<0.05 ;{ }^{* *} p<0.01$.

\section{Discussion}

We compared parent-proxy quality of life, maternal anxiety, and depression between the normal IQ-mild ID group and moderatesevere ID group in children with $\mathrm{CP}$. We hypothesized that parent-proxy QoL, maternal psychopathology would be significantly different between the two groups, and our findings did not support this. However, there were differences in gender, types of birth, and presence of epilepsy between the two groups. There was a significant difference in BFMF severity between the two groups; however, GMFCS severity was not different between the two groups. Children with $\mathrm{CP}$ at different intelligence levels have contradictory results of QoL studies. Our findings were in line with studies showing that QoL scores were similar for children with and without cognitive impairment. ${ }^{33,34}$ However, another large study found that $\mathrm{CP}$ children with cognitive impairment have lower QoL scores in the social support domain, compared to $\mathrm{CP}$ children with normal intelligence. ${ }^{8}$

Four large studies reported that children with $\mathrm{CP}$ have poor QoL, compared to the general population in all domains. The scores in the physical, but not the psychosocial domains, correlated with the level of motor impairment. $833,35,36$ In our study, QoL scores 
did not correlate with the level of gross and bimanual fine motor impairment. Furthermore, there was no correlation between maternal depression and parent proxy-reported QoL. In previous studies examining the relationship between parental depression and proxy reports of QoL, parental depression was negatively correlated with parent proxy-reported QoL, contrary to our results..$^{37,38}$ In our study, maternal anxiety scores correlated with the psychosocial domain of PedsQL-P, this result is consistent with previous studies which showed a negative correlation between BAI scores of mothers and the PedsQL P scores of their CP children. ${ }^{39,40}$ Physical domains of QoL scores correlate well with the severity of motor impairment, but the psychosocial scores are low regardless of the impairment severity. ${ }^{41}$ This finding underlines the importance of factors other than the severity of $\mathrm{CP}$ that may affect QoL in these children. According to our study results, maternal anxiety may be one of the factors affecting the psychosocial domain of QoL. In some studies, family variables such as parenting style and family functioning were found to be important factors affecting the psychosocial aspects of QOL of children with $\mathrm{CP} \cdot{ }^{42,43}$ In future studies, parenting style, and family functioning can be examined along with maternal psychological status. In our study, the ages of children positively correlated with maternal BDI scores. It may be related to the increase in the mother's caregiving burden and the decrease in coping capacity as the child grows with chronic diseases. ${ }^{44}$

Presence of epilepsy correlated with a lower level of intelligence in our study. In Gabis and her colleagues' study ${ }^{6}$, epilepsy was found in disabled individuals (33\%), and both presence of epilepsy and GMFCS levels predicted $29.9 \%$ of variance in the IQ score. In our study, intelligence was associated strongly with BFMF but not GMFCS. CP with epilepsy is more often accompanied by ID than $\mathrm{CP}$ without epilepsy. Correspondingly, $\mathrm{CP}$ with ID is associated with a high risk of developing epilepsy. ${ }^{45,46}$
Our study has some limitations. It is a crosssectional study, and had a small sample size, which precludes the determination of a causal relationship between clinical factors. Only the mother was evaluated as a caregiver. Familial characteristics such as family dynamics, parenting roles, and coping strategies were not evaluated. Emotional and behavioral assessment of children with $\mathrm{CP}$ were not applied, and structured psychiatric interviews for mothers were not implemented by researchers. Additionally, epilepsy rates are generally higher in the moderate-severe ID group as expected, and epilepsy could be an important factor that may affect the QoL of children with $\mathrm{CP}$.

In conclusion, several biopsychosocial factors may be related to OoL in children with $\mathrm{CP}$. Our results demonstrate that maternal anxiety was related to psychosocial QoL in children with $\mathrm{CP}$. Maternal depression scores increased with the age of children with $\mathrm{CP}$ which may also indicate the social support needs of mothers with children of chronic diseases. We could not find an association with intelligence levels and QoL of children with CP, maternal anxiety, maternal depression in our study sample. Further studies may reveal the associations with other biopsychosocial factors in children with cerebral palsy of different intelligence levels by longitudinal study design with larger sample sizes.

\section{Acknowledgement}

We are extremely grateful to all children, their families for taking part.

\section{Author contribution}

The authors confirm contribution to the paper as follows: study conception and design: EA, BGK; data collection: EA, YT, STT; analysis and interpretation of results: BGK, EA, YT, STT; draft manuscript preparation: EA, BGK. All authors reviewed the results and approved the final version of the manuscript. 


\section{Ethical approval}

Ethical approval was obtained from the Ankara University Medical School Research Ethics Committee (ID-No: 04-215-18).

\section{Source of funding}

This research did not receive any specific grant from funding agencies in the public, commercial, or not-for-profit sectors.

\section{Conflict of interest}

The author(s) declare no competing interests.

\section{REFERENCES}

1. Surveillance of cerebral palsy in Europe: a collaboration of cerebral palsy surveys and registers. Surveillance of Cerebral Palsy in Europe (SCPE). Dev Med Child Neurol 2000; 42: 816-824.

2. Patel DR, Neelakantan M, Pandher K, Merrick J. Cerebral palsy in children: a clinical overview. Transl Pediatr 2020; 9: 125-135.

3. Cans C, Guillem P, Arnaud C, et al. Prevalence and characteristics of children with cerebral palsy in Europe. Dev Med Child Neurol 2002; 44: 633-640.

4. Bax M, Goldstein M, Rosenbaum P, et al; Executive Committee for the Definition of Cerebral Palsy. Proposed definition and classification of cerebral palsy, April 2005. Dev Med Child Neurol 2005; 47: 571-576.

5. Beckung E, Hagberg G. Neuroimpairments, activity limitations, and participation restrictions in children with cerebral palsy. Dev Med Child Neurol 2002; 44 : 309-316.

6. Gabis LV, Tsubary NM, Leon O, Ashkenasi A, Shefer S. Assessment of abilities and comorbidities in children with cerebral palsy. J Child Neurol 2015; 30: $1640-1645$.

7. Bertoncelli CM, Altamura P, Vieira ER, Bertoncelli D, Thummler S, Solla F. Identifying factors associated with severe intellectual disabilities in teenagers with cerebral palsy using a predictive learning model. J Child Neurol 2019; 34: 221-229.

8. Arnaud C, White-Koning M, Michelsen SI, et al. Parent-reported quality of life of children with cerebral palsy in Europe. Pediatrics 2008; 121: 54-64.
9. Vos RC, Becher JG, Ketelaar M, et al; PERRIN+ Study Group. Developmental trajectories of daily activities in children and adolescents with cerebral palsy. Pediatrics 2013; 132: 915-923.

10. Carona C, Crespo C, Canavarro MC. Similarities amid the difference: caregiving burden and adaptation outcomes in dyads of parents and their children with and without cerebral palsy. Res Dev Disabil 2013; 34: 882-893.

11. Nam SJ, Park EY. Relationship between caregiving burden and depression in caregivers of individuals with intellectual disabilities in Korea. J Ment Health 2017; 26: 50-56.

12. Park EY, Kim JH. Activity limitation in children with cerebral palsy and parenting stress, depression, and self-esteem: a structural equation model. Pediatr Int 2020; 62: 459-466.

13. Raina P, O'Donnell M, Rosenbaum P, et al. The health and well-being of caregivers of children with cerebral palsy. Pediatrics 2005; 115: 626-636.

14. Yilmaz H, Erkin G, Nalbant L. Depression and anxiety levels in mothers of children with cerebral palsy: a controlled study. Eur J Phys Rehabil Med 2013; 49: 823-827.

15. Ones K, Yilmaz E, Cetinkaya B, Caglar N. Assessment of the quality of life of mothers of children with cerebral palsy (primary caregivers). Neurorehabil Neural Repair 2005; 19: 232-237.

16. Bailey DB Jr, Golden RN, Roberts J, Ford A. Maternal depression and developmental disability: research critique. Ment Retard Dev Disabil Res Rev 2007; 13: 321-329.

17. Singer GH. Meta-analysis of comparative studies of depression in mothers of children with and without developmental disabilities. Am J Ment Retard 2006; 111: 155-169.

18. Chandravanshi G, Sharma KK, Jilowa CS, Meena PS, Jain M, Prakash O. Prevalence of depression in mothers of intellectually disabled children: a crosssectional study. Med J DY Patil Univ 2017; 10: 156161.

19. Li-Tsang CWP, Yau MKS, Yuen HK. Success in parenting children with developmental disabilities: some characteristics, attitudes and adaptive coping skills. Br J Dev Disabil 2001; 47: 61-71.

20. Himmelmann K, Panteliadis CP. Clinical Characteristics. In: Panteliadis CP (ed). Cerebral Palsy (3rd ed) Cham: Springer, 2018: 75-87.

21. Brehaut JC, Kohen DE, Raina P, et al. The health of primary caregivers of children with cerebral palsy: how does it compare with that of other Canadian caregivers? Pediatrics 2004; 114: e182-e191. 
22. Christine C, Dolk H, Platt MJ, Colver A, Prasauskiene A, Krägeloh-Mann I; SCPE Collaborative Group. Recommendations from the SCPE collaborative group for defining and classifying cerebral palsy. Dev Med Child Neurol Suppl 2007; 109: 35-38.

23. Palisano RJ, Rosenbaum P, Bartlett D, Livingston $\mathrm{MH}$. Content validity of the expanded and revised Gross Motor Function Classification System. Dev Med Child Neurol 2008; 50: 744-750.

24. Elvrum AK, Andersen GL, Himmelmann K, et al. Bimanual fine motor function (BFMF) classification in children with cerebral palsy: aspects of construct and content validity. Phys Occup Ther Pediatr 2016; 36: 1-16.

25. Çakın Memik N, Ağaoğlu B, Coşkun A, Karakaya I. Çocuklar için yaşam kalitesi ölçeğinin 8-12 yaş çocuk formunun geçerlik ve güvenirliği. Çocuk ve Gençlik Ruh Sağlığı Dergisi 2008; 15: 87-98.

26. Cakin Memik N, Ağaoğlu B, Coşkun A, Uneri OS, Karakaya I. Çocuklar için yaşam kalitesi ölçeğinin 13-18 yaş ergen formunun geçerlik ve güvenilirliği. Türk Psikiyatri Dergisi 2007; 18: 353-363.

27. Ulusoy M, Sahin NH, Erkmen H. Turkish version of the Beck anxiety inventory: psychometric properties. J Cogn Psychother 1998; 12: 163-172.

28. Hisli N. Beck depresyon envanterinin üniversite öğrencileri için geçerliği, güvenirliği. Türk Psikoloji Dergisi 1989; 7: 3-13.

29. Wechsler D. WISC-R Manual for the Wechsler Intelligence Scale for Children Revised. New York: The Psychological Corporation, 1974.

30. Savasır I, Sahin N. Wechsler Çocuklar İçin Zeka Ölçeği Uygulama Kitapçı̆̆ı. (Çeviren: Savaşır I, Şahin N). Ankara: Türk Psikologlar Derneği, 1995.

31. Uğural Şemin R. Stanford Binet Ölçeğinin İstanbul Çocuklarına Uygulanması. İstanbul: İstanbul Üniversitesi Fen Fakültesi Basım Atölyesi, 1987.

32. Savasır I, Sezgin N, Erol N. Ankara Gelişim Tarama Envanteri (AGTE). 2. ve 3. Basım. Ankara: Türk Psikologlar Derneği, 1998.

33. Wake M, Salmon L, Reddihough D. Health status of Australian children with mild to severe cerebral palsy: cross-sectional survey using the Child Health Questionnaire. Dev Med Child Neurol 2003; 45: 194199.

34. McCarthy ML, Silberstein CE, Atkins EA, Harryman SE, Sponseller PD, Hadley-Miller NA. Comparing reliability and validity of pediatric instruments for measuring health and well-being of children with spastic cerebral palsy. Dev Med Child Neurol 2002; 44: 468-476.
35. Kennes J, Rosenbaum P, Hanna SE et al. Health status of school-aged children with cerebral palsy: information from a population-based sample. Dev Med Child Neurol 2002; 44: 240-247.

36. Vargus-Adams J. Longitudinal use of the Child Health Questionnaire in childhood cerebral palsy. Dev Med Child Neurol 2006; 48: 343-347.

37. Davis E, Mackinnon A, Waters E. Parent proxyreported quality of life for children with cerebral palsy: is it related to parental psychosocial distress? Child Care Health Dev 2012; 38: 553-560.

38. Waters E, Doyle J, Wolfe R, Wright M, Wake M, Salmon L. Influence of parental gender and selfreported health and illness on parent-reported child health. Pediatrics 2000; 106: 1422-1428.

39. Soliman R, Altwairqi R, Alshamrani N, Al-Zahrani A, Al-Towairqi R, Al-Habashi A. Relationship between quality of life of children with cerebral palsy and their mothers' depression and anxiety. Saudi J Health Sci 2019; 8: 1-5.

40. Türkoğlu S, Bilgiç A, Türkoğlu G, Yilmaz S. Impact of symptoms of maternal anxiety and depression on quality of life of children with cerebral palsy. Noro Psikiyatr Ars 2016; 53: 49-54.

41. Aran A. Quality of life in children with cerebral palsy. In: Preedy VR, Watson RR (eds). Handbook of Disease Burdens and Quality of Life Measures. New York: Springer, 2010: 2453-2468.

42. Aran A, Shalev RS, Biran G, Gross-Tsur V. Parenting style impacts on quality of life in children with cerebral palsy. J Pediatr 2007; 151: 56-60.

43. Majnemer A, Shevell M, Rosenbaum P, Law M, Poulin C. Determinants of life quality in school-age children with cerebral palsy. J Pediatr 2007; 151: 470475 .

44. Ribeiro MF, Vandenberghe L, Prudente CO, Vila VD, Porto CC. Cerebral palsy: how the child's age and severity of impairment affect the mother's stress and coping strategies. Cien Saude Colet 2016; 21: 3203-3212.

45. Carlsson M, Hagberg G, Olsson I. Clinical and aetiological aspects of epilepsy in children with cerebral palsy. Dev Med Child Neurol 2003; 45: 371376.

46. Švraka E. Children with cerebral palsy and epilepsy. In: Stevanović D, (ed). Epilepsy-Histological, Electroencephalographic and Psychological Aspects. Croatia: InTech Open Access Publicher, 2012: 251276. 